Journal of Healthcare Technology and Medicine Vol. 4 No. 2 Oktober 2018

Universitas Ubudiyah Indonesia

e-ISSN : 2615-109X

\title{
HUBUNGAN STATUS KESEHATAN, USIA DAN STATUS EKONOMI DENGAN STATUS GIZI IBU HAMIL DI PUSKESMAS JEULINGKE KECAMATAN SYIAH KUALA BANDA ACEH
}

\author{
Relationship Of Health Status, Age And Economic Status With Pregnant \\ Women's Nutrition Status In Jeulingke Health Center, Syiah Kuala Banda \\ Aceh District \\ ${ }^{1}$ Ismiati, ${ }^{2}$ Eka Novia \\ ${ }^{1,2}$ Fakultas Ilmu Kesehatan, Universitas Ubudiyah Indonesia, Banda Aceh \\ Email: ismiati@uui.ac.id
}

\begin{abstract}
ABSTRAK
Kehamilan menyebabkan meningkatnya kebutuhan energi dan zat gizi lainnya untuk pertumbuhan dan perkembangan janin. Berbagai resiko dapat terjadi jika ibu kurang gizi, diantaranya perdarahan, abortus, bayi lahir mati, bayi lahir dengan berat rendah, kelainan congenital dan retardasi mental. Status gizi ibu hamil dapat dipengaruhi suhu lingkungan, status ekonomi dan social, budaya, usia, pendidikan, status kesehatan dan pengetahuan.. Untuk mengetahui hubungan status kesehatan, usia dan status ekonomi dengan status gizi ibu hamil di Puskesmas Jeulingke tahun 2018. Bersifat analitik dengan pendekatan Cross Sectional. Populasi adalah ibu hamil, sampel 49 orang. Pengumpulan data dilakukan dengan mengisi chek list dan menyebarkan kuesioner. Kemudian di uji statistik menggunakan Chi-square memakai program SPSS, Ho ditolak jika p value >0,05 dan $\mathrm{Ha}$ diterima jika $\mathrm{p}$ value $<0,05$. Dari 29 responden dengan status kesehatan sehat mayoritas memiliki status gizi kehamilan yang normal yaitu sebanyak 93,1\% ( $p$ value $=0,000$ ), dari 22 responden yang berusia ideal mayoritas memiliki status gizi kehamilan yang normal yaitu sebanyak $81,8 \%$ ( $\mathrm{p}$ value $=0,030$ ), dan dari 23 responden yang berstatus ekonomi kelas bawah mayoritas memiliki status gizi kehamilan yang tidak normal yaitu sebanyak $56,5 \%$ ( $\mathrm{p}$ value $=0,021$ ). Ada hubungan status kesehatan, usia dan status ekonomi dengan status gizi ibu hamil di Puskesmas Jeulingke tahun 2014. Diharapkan bagi institusi pendidikan agar hasil penelitian ini berguna sebagai sumber bacaan dan bagi masyarakat agar terus meningkatkan pengetahuan tentang pentingnya gizi masa kehamilan.
\end{abstract}

Kata Kunci : Gizi ibu hamil, status kesehatan, usia, status ekonomi 
Journal of Healthcare Technology and Medicine Vol. 4 No. 2 Oktober 2018

Universitas Ubudiyah Indonesia

e-ISSN : 2615-109X

\begin{abstract}
Pregnancy causes an increased need for energy and other nutrients for fetal growth and development. Various risks can occur if the mother is malnourished, including bleeding, abortion, stillbirth, low birth weight babies, congenital abnormalities and mental retardation. The nutritional status of pregnant women can be influenced by environmental temperature, economic and social status, culture, age, education, health status and knowledge. To find out the relationship between health status, age and economic status with the nutritional status of pregnant women in Jeulingke Health Center in 2018. Analytic with Cross Sectional approach. The population was pregnant women, a sample of 49 people. Data collection is done by filling in check lists and distributing questionnaires. Then in the statistical test using Chi-square using the SPSS program, Ho is rejected if p value > 0.05 and Ha is accepted if p value <0.05. Of the 29 respondents with a healthy health status the majority had normal pregnancy nutritional status as many as $93.1 \%$ ( $p$ value $=0,000$ ), of the 22 respondents who were of ideal age the majority had a normal pregnancy nutritional status of $81.8 \%$ ( $p$ value $=0.030$ ), and of the 23 respondents with lower economic status, the majority have an abnormal nutritional status of pregnancy, which is $56.5 \%$ ( $p$ value $=0.021)$. There is a relationship between health status, age and economic status with the nutritional status of pregnant women at the Jeulingke Health Center in 2014. It is hoped that educational institutions will find the results of this study useful as a source of reading and for the community to continue to increase knowledge about the importance of nutrition during pregnancy.
\end{abstract}

Keywords: Nutrition for pregnant women, health status, age, economic status

\title{
PENDAHULUAN
}

Menurut Federasi Obstetri Ginekologi Internasional, kehamilan di definisikan sebagai fertilisasi atau penyatuan dari spermastozoa dan ovum dan dilanjutkan dengan nidasi atau implantasi. Bila dihitung dari saat fertilisasi hingga lahirnya bayi, kehamilan normal akan berlangsung dalam waktu 40 minggu atau 10 bulan lunar atau 9 bulan menurut kalender internasional. Kehamilan terbagi dalam tiga trimester, dimana trimester kesatu berlangsung selama 12 minggu, trimester kedua 15 minggu (minggu ke 13 sampai dengan ke 27), dan trimester ke tiga berlangsung 13 minggu (minggu ke 28 hingga ke 40) (Prawirohardjo, 2010).

Rencana strategi nasional Making Pregnancy Safer (MPS) di Indonesia tahun 2001 sampai 2015 menunjukkan bahwa dalam konteks rencana pembangunan kesehatan menuju Indonesia sehat 2015 adalah di tetapkan misi pembangunan kesehatan yang salah satunya adalah mendorong kemandirian masyarakat untuk hidup sehat, dengan sasaran 
Journal of Healthcare Technology and Medicine Vol. 4 No. 2 Oktober 2018

Universitas Ubudiyah Indonesia

e-ISSN : 2615-109X

meningkatkan jumlah penduduk menkonsumsi makanan dengan gizi seimbang, sehingga

untuk meningkatkan percepatan perbaikan derajat kesehatan masyarakat, salah satu program unggulan perbaikan gizi (Depkes RI, 2011).

Status gizi seorang ibu hamil menurut Gisajel (2011) dapat di pengaruhi oleh beberapa faktor diantaranya yaitu adalah suhu lingkungan, status ekonomi dan social, budaya, usia, pendidikan, status kesehatan dan pengetahuan.

\section{METODOLOGI PENELITIAN}

Penelitian ini merupakan penelitian yang bersifat analitik dengan menggunakan pendekatan Cross Sectional yaitu dimana data yang menyangkut variabel bebas dan variabel terikat akan dikumpulkan dalam waktu yang bersamaan (Notoatmodjo, 2010). Penelitian ini bertujuan untuk mengetahui hubungan status kesehatan, usia dan status ekonomi dengan status gizi ibu hamil di Puskesmas Jeulingke Kecamatan Syiah Kuala Banda Aceh.

Populasi dalam penelitian ini adalah semua ibu hamil yang datang ke Puskesmas Jeulingke Kecamatan Syiah Kuala Banda Aceh tahun 201, dengan total jumlah populasi 94 orang.

\section{Alat Pengumpulan Data}

Alat pengumpulan data pada penelitian ini berupa chek list dan kuesioner berisi tentang :

a. Status gizi ibu hamil

Check list memiliki 2 pilihan jawaban. Bila ukuran LILA " $\geq 23,5$ " maka normal, dan bila ukuran LILA “ $<23,5$ " maka tidak normal. b. Status kesehatan terdiri dari 5 pertanyaan Kuesioner menggunakan Skala Guttman, bila jawaban "Ya", mendapat nilai 1 dan bila jawaban "Tidak" mendapat nilai 0 . Nilai maksimal 5 dan nilai minimal 0.

c. Usia terdiri dari 1 pertanyaan

Kuesioner memiliki 3 pilihan jawaban, yaitu “< 20” “20-35”, dan "> 35".

d. Ekonomi terdiri dari 1 pertanyaan

Kuesioner memiliki 3 pilihan jawaban, yaitu "Lebih dari Rp. 2.000.000", “Rp. 1.000.000 sampai 2.000.000" dan "Di bawah Rp. 1.000.000". 
Journal of Healthcare Technology and Medicine Vol. 4 No. 2 Oktober 2018

Universitas Ubudiyah Indonesia

e-ISSN : 2615-109X

\section{Teknik Pengumpulan Data}

a. Data Primer

Data primer merupakan sumber data yang diperoleh langsung dari sumber asli (tidak melalui perantara) yaitu dari responden langsung (Saputra, 2009). Data primer dalam penelitian ini adalah data yang dikumpulkan langsung dengan menyebarkan kuesioner pada responden tentang status gizi, status kesehatan, usia dan status ekonomi pada ibu hamil.

\section{b. Data Sekunder}

Data sekunder merupakan sumber data penelitian yang diperoleh peneliti secara tidak langsung melalui media perantara (diperoleh dan dicatat oleh pihak lain). Data sekunder umumnya berupa bukti, catatan atau laporan historis yang telah tersusun dalam arsip (data dokumenter) yang dipublikasikan dan yang tidak di publikasikan (Saputra, 2009). Data sekunder dalam penelitian ini adalah data yang di dapat dari buku register di Puskesmas Jeulingke Kecamatan Syiah Kuala Banda Aceh.

\section{HASIL DAN PEMBAHASAN}

\section{Gambaran Umum Lokasi Penelitian}

Puskesmas Jeulingke terletak di Kecamatan Syiah Kuala Banda Aceh serta memiliki batasan wilayah yaitu :

1. Sebelah Barat berbatasan dengan wilayah kerja puskesmas Lampulo Kecamatan Kuta Alam

2. Sebelah Timur berbatasan dengan puskesmas Kopelma Kecamatan Syiah Kuala

3. Sebelah Selatan berbatasan dengan puskesmas Ulee Kareng Kota Banda Aceh

4. Desa Sebelah Utara berbatasan dengan Selat Malaka

Penelitian ini dilakukan di Puskesmas Jeulingke kepada 49 orang responden. Pengumpulan data dilakukan dengan cara mengisi checklist untuk LILA dan menyebarkan kuesioner untuk pertanyaan mengenai status kesehatan, usia, dan ekonomi. Dari pengumpulan data tersebut, maka diperoleh hasil sebagai berikut: 
Journal of Healthcare Technology and Medicine Vol. 4 No. 2 Oktober 2018

Universitas Ubudiyah Indonesia

e-ISSN : 2615-109X

a. Status gizi ibu hamil

Tabel 5.1

Distribusi frekuensi gizi ibu hamil pada Responden di Puskesmas Jeulingke Kecamatan Syiah Kuala Banda Aceh Tahun 2018

\begin{tabular}{lcc}
\hline \multicolumn{1}{c}{ Status zizi ibu hamil } & Frekuensi & $\%$ \\
\hline Normal & 31 & 63,3 \\
Tidak normal & 18 & 36,7 \\
\hline \multicolumn{1}{c}{ Total } & 49 & 100 \\
\hline
\end{tabular}

Berdasarkan tabel 5.1 dapat diketahui bahwa dari 49 responden mayoritas memiliki status gizi kehamilan yang normal yaitu sebanyak 31 responden $(63,3 \%)$.

b. Status kesehatan

Tabel 5.2

Distribusi frekuensi status kesehatan pada Responden di Puskesmas Jeulingke Kecamatan Syiah Kuala Banda Aceh Tahun 2018

\begin{tabular}{|c|c|c|}
\hline Status kesehatan & Frekuensi & $\%$ \\
\hline Sehat & 29 & 59,2 \\
\hline Sakit & 20 & 40,8 \\
\hline Total & 49 & 100 \\
\hline
\end{tabular}

Berdasarkan tabel 5.2 dapat diketahui bahwa dari 49 responden mayoritas memiliki status kesehatan yang sehat yaitu sebanyak 29 responden $(59,2 \%)$.

Usia

Tabel 5.3

Distribusi frekuensi usia pada Responden di Puskesmas Jeulingke Kecamatan Syiah Kuala Banda Aceh Tahun 2018

\begin{tabular}{|c|c|c|}
\hline Usia & Frekuensi & $\%$ \\
\hline Muda & 16 & 32,7 \\
\hline Ideal & 22 & 44,9 \\
\hline
\end{tabular}


Journal of Healthcare Technology and Medicine Vol. 4 No. 2 Oktober 2018

Universitas Ubudiyah Indonesia

e-ISSN : 2615-109X

\begin{tabular}{|c|c|c|}
\hline Tua & 11 & 22,4 \\
\hline Total & 49 & 100 \\
\hline
\end{tabular}

Berdasarkan tabel 5.3 dapat diketahui bahwa dari 49 responden mayoritas berusia ideal yaitu sebanyak 22 responden $(44,9 \%)$.

d. Status ekonomi

Tabel 5.4

Distribusi frekuensi ekonomi pada Responden di Puskesmas Jeulingke Kecamatan Syiah Kuala Banda Aceh Tahun 2018

\begin{tabular}{lcc}
\hline \multicolumn{1}{c}{ Ekonomi } & Frekuensi & $\%$ \\
\hline Kelas atas & 9 & 18,4 \\
Kelas menengah & 17 & 34,7 \\
Kelas bawah & 23 & 46,9 \\
\hline \multicolumn{1}{c}{ Total } & 49 & 100 \\
\hline
\end{tabular}

Berdasarkan tabel 5.4 dapat diketahui bahwa dari 49 responden mayoritas memiliki status ekonomi kelas bawah yaitu sebanyak 23 responden $(46,9 \%)$.

\section{- Hubungan status kesehatan dengan status gizi ibu hamil}

Berdasarkan hasil penelitian dapat diketahui bahwa dari 29 responden dengan status kesehatan sehat mayoritas memiliki status gizi kehamilan yang normal yaitu sebanyak $93,1 \%$ dan dari 20 responden dengan status kesehatan sakit mayoritas memiliki status gizi kehamilan yang tidak normal yaitu sebanyak $80 \%$.

Hasil analisis statistik dengan menggunakan uji chi-square diperoleh pvalue = 0,000 atau $\mathrm{p}<0,05$ yang artinya Ha diterima dan ada hubungan status kesehatan dengan status gizi ibu hamil di Puskesmas Jeulingke Kecamatan Syiah Kuala Banda Aceh tahun 2018.

Kebutuhan gizi pada masa hamil meningkat karena dibutuhkan untuk persiapan 
Journal of Healthcare Technology and Medicine Vol. 4 No. 2 Oktober 2018

Universitas Ubudiyah Indonesia

e-ISSN : 2615-109X

produksi ASI dan tumbuh kembang janin. Kondisi sakit dan jenis penyakit akan mempengaruhi kebutuhan gizi seseorang. Sebagai contoh, ibu hamil yang menderita diabetes mellitus harus memperhatikan asupan energy, sedangkan ibu hamil yang menderita tekanan darah tinggi harus memperhatikan asupan natrium (Sulistyoningsih, 2011).

Hasil penelitian ini sejalan dengan teori yang disampaikan oleh Kristiyanasari (2010), yaitu status kesehatan kemungkinan sangat berpengaruh terhadap nafsu makan seseorang yang berefek kepada status gizi orang tersebut termasuk ibu hamil. Seorang ibu hamil yang dalam keadaan sakit otomatis akan memiliki nafsu makan yang berbeda dengan ibu yang dalam keadaan sehat.

Namun ibu harus ingat, bahwa gizi yang ia dapat akan dipakai untuk dua kehidupan yaitu bayi dan dirinya Menurut asumsi peneliti, status kesehatan sangat berhubungan dengan status gizi ibu hamil karena ibu hamil yang dalam keadaan sakit akan memiliki nafsu makan yang cenderung kurang, dan bagi ibu hamil yang menderita beberapa penyakit selama kehamilan seperti hypertensi, hyperemisis, diabetes, dan lainnya, maka harus sangat mengontrol makanan yang dikonsumsinya karena ibu hamil dengan kondisi demikian memiliki beberapa kebutuhan makanan khusus agar gizinya tetap terpenuhi dan kondisi ibu hamil dapat sehat kembali.

\section{Hubungan usia dengan status gizi ibu hamil}

Berdasarkan hasil penelitian dapat diketahui bahwa dari 16 responden yang berusia muda mayoritas memiliki status gizi kehamilan yang normal yaitu sebanyak 56,2\%, dari 22 responden yang berusia ideal mayoritas memiliki status gizi kehamilan yang normal yaitu sebanyak $81,8 \%$ dan dari 22 responden yang berusia tua mayoritas memiliki status gizi kehamilan yang tidak normal yaitu sebanyak 63,6\%.

Hasil analisis statistik dengan menggunakan uji chi-square diperoleh p value $=0,030$ 
Journal of Healthcare Technology and Medicine Vol. 4 No. 2 Oktober 2018

Universitas Ubudiyah Indonesia

e-ISSN : 2615-109X

atau $\mathrm{p}<0,05$ yang artinya Ha diterima dan ada hubungan usia dengan status gizi ibu hamil

di Puskesmas Jeulingke Kecamatan Syiah Kuala Banda Aceh tahun 2018.

Usia diperlukan untuk menentukan besaran kalori serta zat gizi yang akan diberikan.

Usia akan mempengaruhi kemampuan atau pengalaman yang dimiliki seseorang dalam pemenuhan nutrisi (Nursalam, 2004). 
Journal of Healthcare Technology and Medicine Vol. 4 No. 2 Oktober 2018

Universitas Ubudiyah Indonesia

e-ISSN : 2615-109X

Hasil penelitian ini sejelan dengan teori yang disampaikan oleh Kristiyanasari (2010), yaitu semakin muda dan semakin tua umur seorang ibu hamil akan berpengaruh terhadap kebutuhan gizi yang banyak karena selain digunakan untuk pertumbuhan dan perkembangan dirinya sendiri juga harus berbagi dengan janin yang sedang dikandungnya. Sedangkan untuk umur yang tua perlu energy yang besar juga karena fungsi organ yang makin melemah dan diharuskan bekerja maksimal maka memerlukan tambahan energy yang cukup guna mendukung kehamilan yang sedang berlangsung.

Menurut asumsi peneliti, kondisi kehamilan sangat berhubungan dengan usia, termasuk masalah gizi. Karena selama kehamilah gizi dibutuhkan oleh 2 manusia yaitu untuk ibu dan janin. Ibu hamil yang berusia terlalu muda masih membutuhkan zat gizi untuk pertumbuhannya, sedangkan ibu yang hamil pada usia yang tua, mungkin secara psikologis akan lebih siap menerima kehamilan, namun pada usia yang tua organ tubuh ibu sudah mulai melemah serta dengan adanya kehamilan maka tubuh ibu akan bekerja lebih keras. Usia yang baik uuntuk kehamilan adalah pada usia yang ideal, karena pada usia tersebut, seorang wanita akan siap menghadapi kehamilan baik secara psikologis maupun organ-organ tubuhnya.

\section{Hubungan status ekonomi dengan status gizi ibu hamil}

Berdasarkan hasil penelitian dapat diketahui bahwa dari 9 responden yang berstatus ekonomi kelas atas mayoritas memiliki status gizi kehamilan yang normal yaitu sebanyak 88,9\%, dari 17 responden yang berstatus ekonomi kelas menengah mayoritas memiliki status gizi kehamilan yang normal yaitu sebanyak 76,5\% dan dari 23 responden yang berstatus ekonomi kelas bawah mayoritas memiliki status gizi kehamilan yang tidak 
Journal of Healthcare Technology and Medicine Vol. 4 No. 2 Oktober 2018

Universitas Ubudiyah Indonesia

e-ISSN : 2615-109X

normal yaitu sebanyak

$56,5 \%$.

Hasil analisis statistik dengan menggunakan uji chi-square diperoleh $\mathrm{p}$ value $=0,021$ atau $\mathrm{p}<0,05$ yang artinya Ha diterima dan ada hubungan status ekonomi dengan status gizi ibu hamil di Puskesmas Jeulingke Kecamatan Syiah Kuala Banda Aceh tahun 2018.

Status ekonomi adalah kedudukan seseorang atau keluarga di masyarakat berdasarkan pendapatan per bulan. Status ekonomi dapat dilihat dari pendapatan yang disesuaikan dengan harga barang pokok (Kartono, 2006). Status ekonomi berguna untuk pemastian ibu mampu membeli dan memilih bahan makanan yang bernilai gizi tinggi (Arisman, 2009).

Hasil penelitian ini sejalan dengan teori yang disampaikan oleh Sulistyoningsih (2011), yaitu ekonomi cukup dominan dalam mempengaruhi konsumsi pangan. Meningkatnya pendapatan akan meningkatkan peluang untuk membeli pangan dengan kualitas dan kuantitas yang lebih baik, sebaliknya penurunan pendapatan akan menyebabkan menurunya daya beli pangan baik secara kualitas maupun kuantitas.

Menurut asumsi peneliti, status ekonomi jelas berhubungan dengan status gizi ibu hamil. Pada keluarga yang memiliki status ekonomi kelas atas, maka akan memiliki kemampuan yang lebih untuk membeli dan memilih makanan yang berkualitas dan bergizi walaupun dengan harga yang mahal. Sehingga ibu hamil dengan ekonomi kelas atas akan jarang mengalami gizi yang tidak normal. Pada ibu hamil yang ekonominya menengah, maka kebutuhan juga akan dapat terpenuhi yaitu dengan membeli makanan yang bergizi namun dengan harga yang terjangkau, sedangkan pada ibu hamil yang status ekonominya kelas bawah, mungkin dalam kesehariannya makan cukup sekedar makan agar tidak lapar dan mengabaikan masalah gizi, karena pada yang demikian meskipun mengetahui jenis 
Journal of Healthcare Technology and Medicine Vol. 4 No. 2 Oktober 2018

Universitas Ubudiyah Indonesia

e-ISSN : 2615-109X

makanan yang begizi namun memiliki keterbatasan sehingga tidak mampu membelinnya dan akhirnya cenderung mengalami status gizi yang tidak normal.

\section{KESIMPULAN}

Setelah dilakukan penelitian dan uji statistik dengan menggunakan chi-square tentang hubungan status kesehatan, usia dan status ekonomi dengan status gizi ibu hamil di Puskesmas Jeulingke Kecamatan Syiah Kuala Banda Aceh tahun 2018, maka dapat disimpulkan bahwa :

1. Ada hubungan status kesehatan dengan status gizi ibu hamil di Puskesmas Jeulingke Kecamatan Syiah Kuala Banda Aceh tahun 2018 (p value = 0,000< $0,05)$.

2. Ada hubungan usia dengan status gizi ibu hamil di Puskesmas Jeulingke Kecamatan Syiah Kuala Banda Aceh tahun 2018 ( $\mathrm{p}$ value = 0,030<0,05).

3. Ada hubungan status ekonomi dengan status gizi ibu hamil di Puskesmas Jeulingke Kecamatan Syiah Kuala Banda Aceh tahun 2018 ( $\mathrm{p}$ value = 0,021 < $0,05)$.

\section{Saran}

Hasil penelitian ini agar dapat dimanfaatkan sebagai sumber pengetahuan baru serta pengalaman selama penelitian dapat berguna untuk penelitian- penelitian selanjutnya 
Journal of Healthcare Technology and Medicine Vol. 4 No. 1 April 2018

Universitas Ubudiyah Indonesia

e-ISSN : 2615-109X

\section{DAFTAR PUSTAKA}

Adriani, M. \& Wijatmadi, B. 2012. Pengantar gizi Masyarakat. Kencana. Jakarta

Arisman. 2009. Gizi dalam Daur Kehidupan. EGC. Jakarta

Bidanku. 2011. Usia Ideal Wanita untuk Hamil dan Melahirkan. http://bidanku.com /usia-ideal-wanita-untuk-hamil-dan-melahirkan. (Diakses 19 Januari 2014).

Departemen Kesehatan. 2011. Gizi dan Kesehatan Masyarakat. Balai Pustaka. Jakarta

Effendy, Nasrul. 2001. Keperawatan Kesehatan Masyarakat. EGC. Jakarta

Gisajel. 2011. 2011. Faktor-Faktor Yang Mempengaruhi Status Gizi Ibu Hamil. http://www.lusa.web.id/faktor-faktor-yang-mempengaruhi-gizi-ibu (Diakses 19 Januari 2014).

Gisajel. 2011. Faktor-faktor yang mempengaruhi status gizi ibu hamil. http:// www.lusa .web.id/faktor-faktor-yang-mempengaruhi-gizi-ibu-hamil/. (Diakses 19 Januari 2014).

Saputra. 2009. Data Sekunder Dan Data Primer. http://nagabiru86.wordpress. com /2009/06/12/data-sekunder-dan-data-primer/. (Diakses pada 26 Januari 2014).

Soetjiningsih. 2004. Tumbuh Kembang Anak. EGC. Jakarta

Sulistyoningsih, Hariani. 2011. Gizi untuk Kesehatan Ibu dan Anak. Graha Ilmu. Yogyakarta. 